\title{
Synthesis and Characterization of 2, 6-Di-(4'-Methyl Phenyl) Pyrylium Fluoroborate and Perchlorate in Single Step Salts Using 4'-Methyl Acetophenone
}

\author{
Jinhyeong Wie'1, Young Min Hong ${ }^{1}$, Hyunook Kim¹, Kyung-Hoon Kim², and Sung-Il Cho²,+
}

\begin{abstract}
Due to its high conductivity, pyrylium has been frequently used in electron transfer reactions or in the synthesis of various organic materials. It has also been used as a sensor material. Traditionally, the compounds have been synthesized using various methods; mostly in a multiple steps. In this study, two pyrylium salts, 2, 6-di-(4'-methylphenyl) pyrylium fluoroborate and perchlorate were synthesized. The synthesis of these products was confirmed by 1H-NMR, LC/TOF-MS and FT-IR analyses while their photo-properties were analyzed using UV/VIS spectrophotometry. In addition, the electron transfer capacities of the salts were analyzed with a conductivity meter, it was found that their electron conductivities were high. When the synthesized compounds were dissolved in acetone, a green fluorescent material was observed to form. The fluorescent material can be used as a sensitizer in the electrical industry.
\end{abstract}

Keywords : Pyrylium Salts, Synthesis, Sensitizer, LC/TOF-MS, UV-vis

\section{INTRODUCTION}

In recent years, positively charged pyrylium salts have been attracting attention from chemists. A pyrylium cation and its derivative are conjugated 6-membered carbon ring systems with one carbon atom replaced with a positively charged oxygen atom(i.e., an oxonium ion). Unlike in other compounds, the oxonium ion in a pyrylium compound is much less reactive due to aromatic stabilization. However, if a pyrylium containing salt is present in water at a neutral $\mathrm{pH}$, it becomes unstable like ordinary oxonium salts. The high electronegativity of the oxygen results in the strongest single perturbation of the one heteroatom in a six-membered ring[1,2], and pyrylium ions have the highest conductivity among the compounds with benzene rings. The high conductivity of pyrylium ions can form different derivatives that can be utilized in a variety of products such as functional pigments, nonlinear optical glasses, phototherapeutic agents and anticancer medicine[3-6].

${ }^{1}$ Department of Energy and Environmental System Engineering, University of Seoul

2Department of Chemical Engineering, University of Seoul

${ }^{+}$Corresponding author: sijo@uos.ac.kr

(Received : Nov. 29, 2011, Revised : Dec. 20, 2011, Accepted : Jan. 4, 2012)
The reactivity of pyrylium salts towards nucleophiles allows them to easily obtain electrons from any compound with aromatic rings, as such, they react with nucleophiles in the 2, 4 and 6 positions, which may result in ringopening. In fact, the reactivity of pyrylium makes it useful in many different fields.

First, pyrylium salt is a main source of two-photon absorption, which can be applied in two-photon microscopy, optical power limiting, single molecule detection, micro-fabrication and 3-dimensional data storage[7, 8]. Since some pyrylium salts even have high photoluminescence so they are excellent candidates for laser technology[6].

Second, due to their complex heterocyclic skeletons and physical properties, pyrylium salts are utilized in pharmaceutical material synthesis as a versatile synthetic intermediate. For example, a novel 3-arylisoquinoline can be synthesized by electrophilically cyclizing pyrylium compounds. 3-arylisoquinoline derivatives are valuable intermediates in the synthesis of morphinan derivatives, especially dextromethorphan[9].

Third, pyrylium salts are a kind of ionic liquid crystal that can be used in displays[10,11].

Fourth, materials with photoelectric characteristic are 
useful as a sensor material. In fact, pyrylium salts have been used in biochemical optical sensors and ion detectors[12-14].

Finally, it is known that the absorption spectrum bands of the unsubstituted pyrylium cation, at $\lambda_{\max }$ of 219 and $269 \mathrm{~nm}$, correspond to the transition from $\pi$ to $\pi^{*}$. Any material with a high UV absorption capacity can be used as a sensing membrane or a sensitizer, as such, pyrlium salts have been utilized in designing sensors for anions, amines, amino acids and proteins[15].

Traditionally, pyrylium salts have been synthesized in multiple steps; the synthesis reactions precede one after the other[16]. The followings are examples of these multi-step pyrylium synthesis processes. 2, 4, 6-trimethylfurano[3, 2c]pyrylium perchlorate as shown in Fig. 1 is synthesized by acetylating 2-methyl-5-acetonylfuran, which is obtained by a reduction of the product from alkaline condensation of furfural with nitroethane[17].
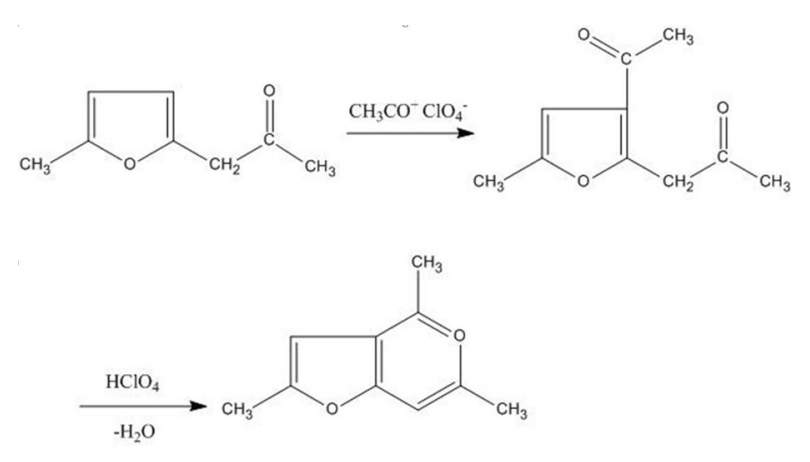

$\mathrm{ClO}_{3}^{-}$

Fig. 1. Example of pyrylium salt synthesis.

2, 4, 6-tris(dialkylamino)pyrylium salts and 2, 6bis(dialkyl-amino)pyran-4-pyrylium as well as their thioanalogues, are prepared by a multi-step route starting with 1, 1, 5, 5-tetrachloro-penta-1, 4-dien-3-one. The tris(dialkylamino)-subs-tituted undergoes electrophilic substitution [18]. The above-mentioned methods, however, take considerable time and their yields are low; the yield of the first method is only $17 \%[1,17]$, for example.

In this study, we synthesized 2, 6-di-(4'-methyl) pyrylium fluoroborate and perchlorate in one step[16]. The syntheses of 2, 6-di-(4'-methyl) pyrylium salt was confirmed by analyzing the products with ${ }^{1} \mathrm{H}-\mathrm{NMR}$, LC/TOF-MS and FT-IR. A UV-VIS spectrophotometer was used to characterize the UV absorption capacity of the products[19]. Finally, the conductivity of the produced salts was also analyzed.

\section{DESIGN}

\subsection{Materials}

Analytical-grade chemicals including aceticanhydride(96\%, Daejung, Korea), fluoroboric acid(50 wt $\%$, Alfa Aesar, USA), perchloric acid(60\%, hayashi purechemical, Japan), 4'-methyl acetophenone(95\%, Aldrich, USA), triethyl orthoformate(98\%, Acros organics, USA) and diethyl ether(99\%, Daejung, Korea) were purchased and used in this study. These materials were not further refined before use.

${ }^{1} \mathrm{H}-\mathrm{NMR}$ (Inova AS400, Varian, USA), LC/IT-TOFMS(Shimadzu, Japan) and an FT-IR(Spectrum RX, Perkin-Elmer, USA) instruments were used to analyze the structure of the synthesized 2, 6-di-(4'-methyl phenyl) pyrylium.

The UV absorption capacity of the salt was analyzed by a UV/VIS spectrometer(S-4100, SCINCO, Korea). The conductivity and melting point were measured by an electrical conductivity meter(EcoMet, Woongki, Korea), and a J-293(JISICO, Korea), respectively.

\subsection{Experiment}

\subsubsection{Synthesis step}

The theoretical synthetic reaction of the salt is illustrated in Fig. 2. The synthesis is initiated with an exothermic reaction between 4'-methyl acetophenone and triethethyl orthoformate.

This reaction spontaneously proceeds through step (a) and (b) (Fig. 2). In this reaction, acetic-anhydride along with fluoroboric acid or perchloric acid can be used as an accelerator; the hydro ion in the mixture attacks one of the oxonium ion of the compound shown in Fig. 2(b). Finally, the oxonium ion is removed to synthesize 2,6-di-(4'-methyl phenyl) pyrylium fluoroborate (or perchlorate) salt, which is substituted with a tetrafluoroborate (or perchlorate) anion via anion-bonding. 

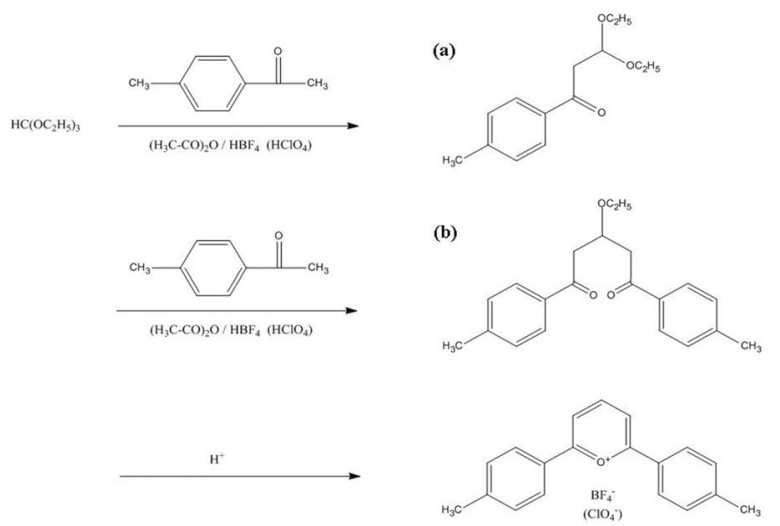

Fig. 2. Mechanism of synthesis of 2, 6-di-(4'-methyl phenyl) pyrylium salts.

\subsubsection{Experiment procedure}

In our study, 2, 6-di-(4'-methyl) pyrylium salt was synthesized in a single step by mixing two previously prepared solutions, i.e., solutions A and B that are shown in Fig. 3. First, solution A was prepared by slowly adding fluoroboric acid(5.9 g) or perchloric acid( $6.7 \mathrm{~g})$ into aceticanhydride $(20 \mathrm{~mL})$ for $30 \mathrm{~min}$ at $5{ }^{\circ} \mathrm{C} \sim 10{ }^{\circ} \mathrm{C}$. To release the heat from the resulting exothermic reaction, the solution was placed in an ice bath filled with acetone.

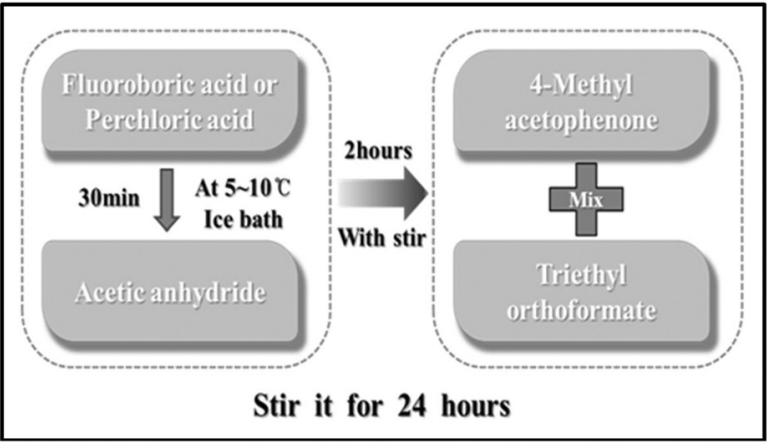

Fig. 3. Experiment procedure to synthesize pyrylium salts in a single step.

Solution B was prepared by slowly adding 4'-methyl acetophenone $(10 \mathrm{~g})$ into $20 \mathrm{~mL}$ of triethyl orthoformate for two hours. After solution (B) was cooled, it was added to solution (A). Then the mixture was stirred for $24 \mathrm{~h}$ to precipitate the pyrylium salt. Finally, the synthesized pyrylium salt was harvested from the solution by applying a vacuum for $30 \mathrm{~min}$.

The structure of the harvested product was analyzed by high resolution LC/IT-TOF-MS and ${ }^{1} \mathrm{H}-\mathrm{NMR}$ spectroscopy.

Samples for analysis were prepared by dissolving $80 \mathrm{mg}$ of the product in $100 \mathrm{~mL}$ of acetone. Samples for FT-IR analysis were prepared by mixing $2 \mathrm{mg}$ of this with 100 $\mathrm{mg}$ of KBr. For UV-VIS analysis, samples were prepared by dissolving $0.8 \mathrm{~g}$ of salt in $100 \mathrm{~mL}$ of acetonitrile. By analyzing the UV/VIS light absorbed by the product, its optical properties were confirmed. Finally, the conductivity of the product was analyzed by measuring the conductance of 0.001 to $0.01 \mathrm{M}$ sample solutions prepared by adding the product salts to acetone at $7{ }^{\circ} \mathrm{C}$. Once the product was dissolved in acetone, it produced brown or green fluorescent light.

\section{RESULTS AND DISCUSSIONS}

In this study, two pyrylium salts were synthesized(Table 1), i.e., 2, 6-di-(4'-methyl phenyl) pyrylium perchlorate (yellow colored), and 2, 6-di-(4'-methyl phenyl)pyrylium fluoroborate(brown colored). The yield of 2, 6-di-(4'methyl phenyl) pyrylium perchlorate was higher than that of fluoroborate salt; the yield of former was $69 \%$, while that of latter was $53 \%$. Compared to pyrylium yields reported in other literature $[1,16]$, ours are slightly or considerable higher.

Table 1. The physical properties of the pyrylium salts produced in this study

\begin{tabular}{|c|c|c|c|c|c|}
\hline & $\begin{array}{l}\text { Compound } \\
\text { name }\end{array}$ & $\begin{array}{l}\text { Melting } \\
\text { point, }{ }^{\circ} \mathrm{C}\end{array}$ & $\begin{array}{c}\text { Empirical } \\
\text { formula }\end{array}$ & Color & $\begin{array}{c}\text { Yield } \\
(\%)\end{array}$ \\
\hline 1 & $\begin{array}{c}\text { 2, 6-id-(4'- } \\
\text { methylpheny1) } \\
\text { pyrylium } \\
\text { fluoroborate }\end{array}$ & 210 & $\begin{array}{c}\mathrm{C}_{19} \mathrm{H}_{17} \mathrm{O}^{+} . \\
\mathrm{BF}_{4^{-}}\end{array}$ & Brown & 52.65 \\
\hline 2 & $\begin{array}{c}\text { 2, 6-id-(4'- } \\
\text { methylpheny1) } \\
\text { pyrylium } \\
\text { perchlorate }\end{array}$ & 240 & $\begin{array}{c}\mathrm{C}_{19} \mathrm{H}_{17} \mathrm{O}^{+} . \\
\mathrm{C} 10_{4}^{-}\end{array}$ & Yellow & 69.42 \\
\hline
\end{tabular}

After each salt product was harvested, its structure was analyzed with 1H-NMR to confirm the synthesis of 2, 6-di(4'-methyl phenyl) pyrylium salts. The peaks from $1 \mathrm{H}-$ NMR analysis of the salts were compared to those with other reference compounds with a similar chemical 
structure(Fig. 4(a)). Fig. 4(a) shows the respective peaks of the synthesized products at 2.5, 7.6, 8.4, 8.8, and $9.2 \mathrm{ppm}$. The ratio of proton atoms was 6:4:4:2:1 in the 2, 6-di-(4'methyl phenyl) pyrylium fluoroborate. Similarly, 2, 6-di(4'-methyl phenyl) pyrylium perchlorate had an almost equivalent area and location to pyrylium fluoroborate salt (Fig. 4(b))[20, 21].

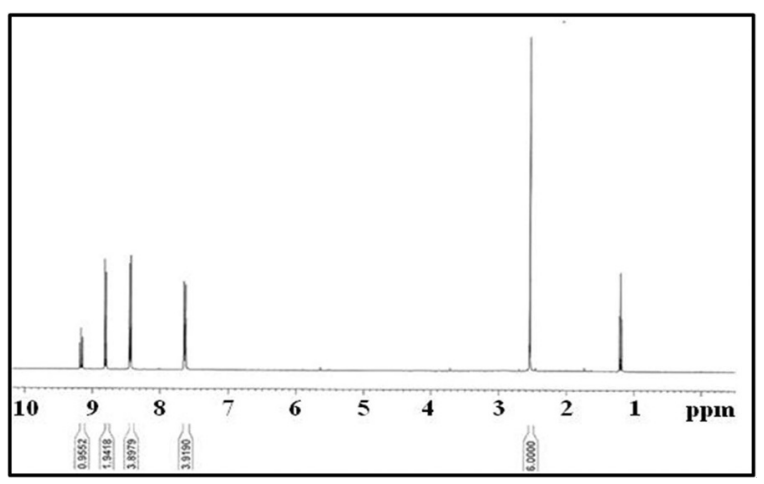

(a)

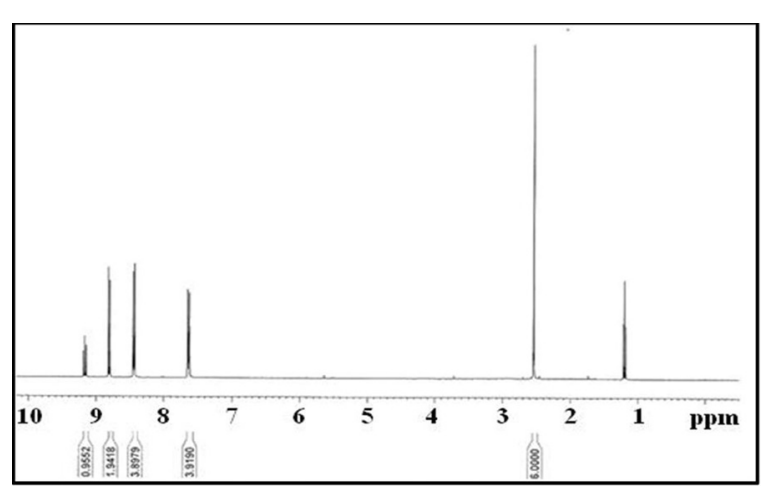

(b)

Fig. 4. 1H-NMR spectra of 2, 6-di-(4'-methyl phenyl) pyrylium fluoroborate (a), and 2, 6-di-(4'-methyl phenyl) pyrylium perchlorate (b).

Analysis of the product with a mass spectrometer(in this study, LC/IT-TOF-MS was used) also confirmed the existence of $\left[\mathrm{C}_{19} \mathrm{H}_{17} \mathrm{O}\right]^{+}$fragment ions with $\mathrm{m} / \mathrm{z}=$ 261.1(Figs. 5(a) and (b)). Considering the accuracy of our test setup the error in the $\mathrm{m} / \mathrm{z}$ of 261.1 is estimated to be only $0.00012 \%$.

The two synthesized salts were also analyzed by FT-IR (Figs. 6(a) and (b)). The peaks in the FT-IR analysis were observed at around 1,600 $\mathrm{cm}^{-1}$ and 2,900 $\mathrm{cm}^{-1}$. The peaks had similar areas, so we can say the analyzed salts are very similar to each other in their structures[4, 17]. In short, the
FT-IR analysis identified the product as 2, 6-di-(4'-methyl phenyl) pyrylium salt[11].

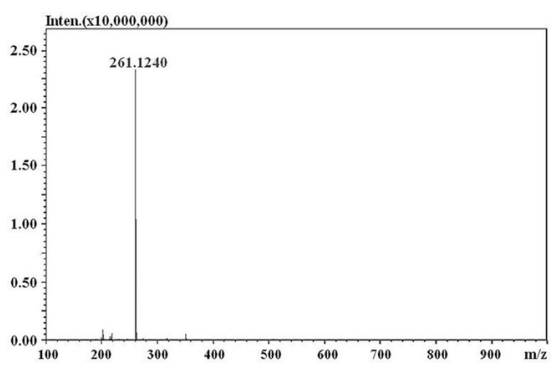

(a)

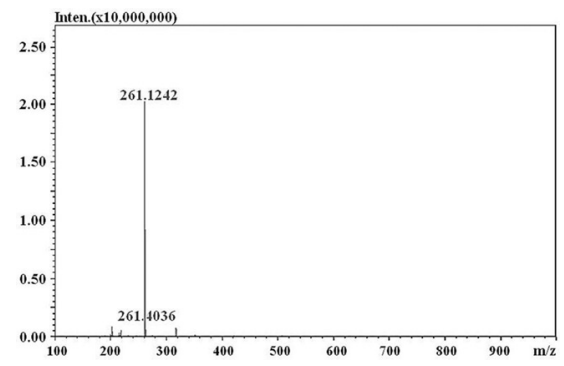

(b)

Fig. 5. LC/TOF-MS spectra of 2, 6-di-(4'-methyl phenyl) pyrylium fluoroborate (a), and 2, 6-di-(4'-methyl phenyl) pyrylium perchlorate (b).

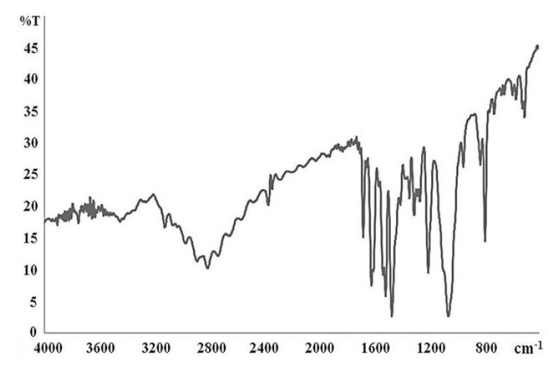

(a)

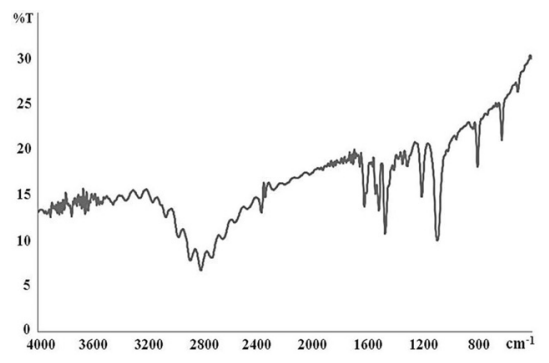

(b)

Fig. 6. FT-IR spectra of 2, 6-di-(4'-methyl phenyl) pyrylium fluoroborate (a), and 2, 6-di-(4'-methyl phenyl) pyrylium perchlorate (b). 
After the structure of the synthesized pyrylium salts was confirmed their physical properties, such as melting point, optical absorption, and electron transferring capacities, were analyzed. The melting point of the synthesized pyrylium perchlorate salt was higher than that of the pyrylium fluoroborate. It is advantageous for the pyrylium salt to have a high melting point because LCDs are heated by other components[22]. The former's melting point was found to be $240{ }^{\circ} \mathrm{C}$, while the latter's was $210{ }^{\circ} \mathrm{C}$.

To analyze optical properties of the 2, 6-di-(4'-methyl phenyl) pyrylium salts, UV-VIS spectra were analyzed. The UV-VIS spectra of the two salts confirmed that there was conjugated $\pi$ bonding. Theoretically, three aromatic rings commonly have a $\lambda_{\max }$ at $350 \mathrm{~nm} 450 \mathrm{~nm}$. The $2,6-$ di-(4'-methyl phenyl) pyrylium salts synthesized in our study showed a $\lambda_{\max }$ at $439 \mathrm{~nm}$ (Fig. 7), indicating the presence of aromatic rings.

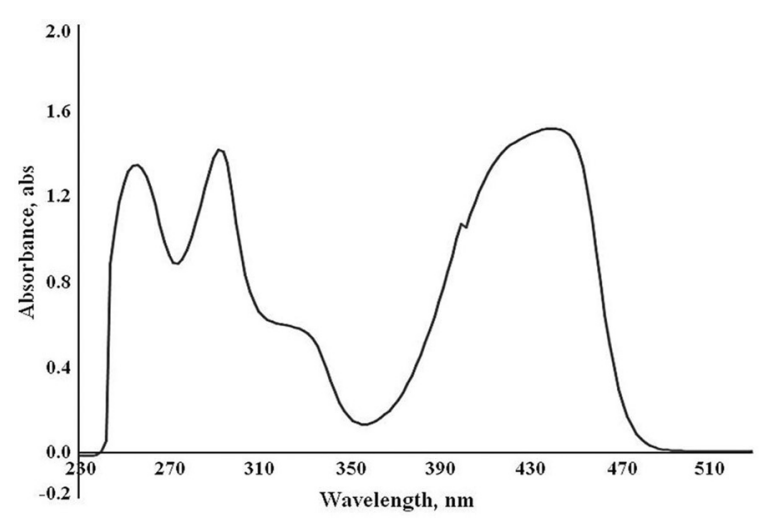

(a)

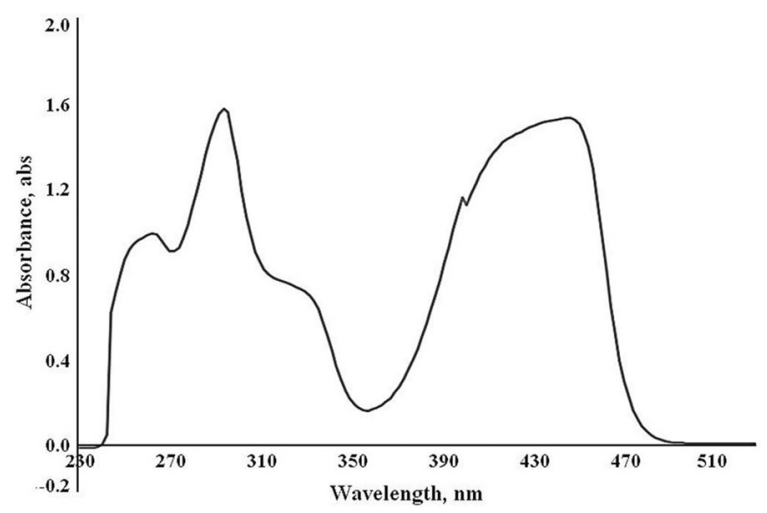

(b)

Fig. 7. UV-VIS spectra of 2, 6-di-(4'-methyl phenyl) pyrylium of 2 , 6-di-(4'-methyl phenyl) pyrylium fluoroborate (a), and 2, 6-di(4'-methyl phenyl) pyrylium perchlorate (b).
Finally, the electron transfer capacities of the synthesized 2, 6-di-(4'-methyl phenyl) pyrylium salts were measured with a conductivity meter(Fig. 8(a) and (b)). These pyrylium salts had higher conductivity than others in organic compounds such as sodium hydroxide, sodium chloride, potassium chloride and so on, but a little lower than those found in electrolytes such as polymers with lithium perchlorate and trifluoromethane sulfonate(Table 2).

Table 2. Conductivity of selected compounds( $0.05 \mathrm{M})[23,24]$

\begin{tabular}{ccc}
\hline \hline value & Compound name & $\mathrm{EC}(\mu \mathrm{S} / \mathrm{cm})$ \\
\hline \multirow{2}{*}{ Reference } & $\mathrm{Nacl}$ ( in water) & 221 \\
(Experimental) & $\mathrm{KCL}$ (in water) & 129 \\
& $\mathrm{NaOH}$ (in water) & 107 \\
& $\mathrm{LiC10}_{4}$ (in EtOH) & $6.0^{*} 10^{6}$ \\
& $\mathrm{NaCF}_{3} \mathrm{SO}_{3}$ (in water) & $8.2 * 10^{6}$ \\
\hline \multirow{3}{*}{ Measurement } & 2, 6-id-(4'-methylpheny1) & $3.10^{*} 10^{3}$ \\
& pyrylium perchlorate(in Acetone) & \\
& $2,6-$-id-(4'-methylpheny1) & $3.38^{*} 10^{3}$ \\
\hline \hline
\end{tabular}

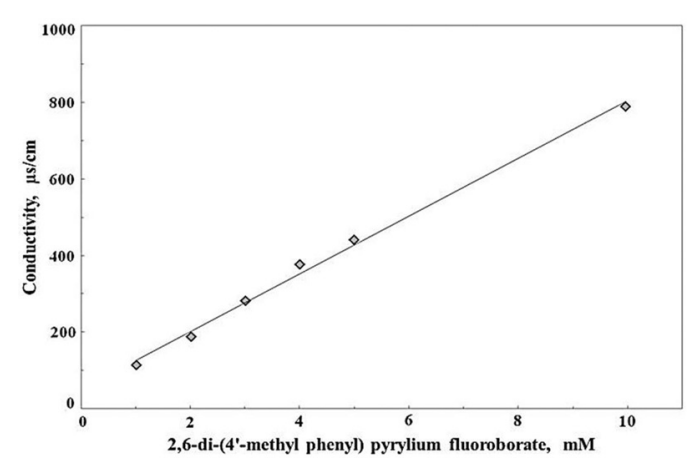

(a)

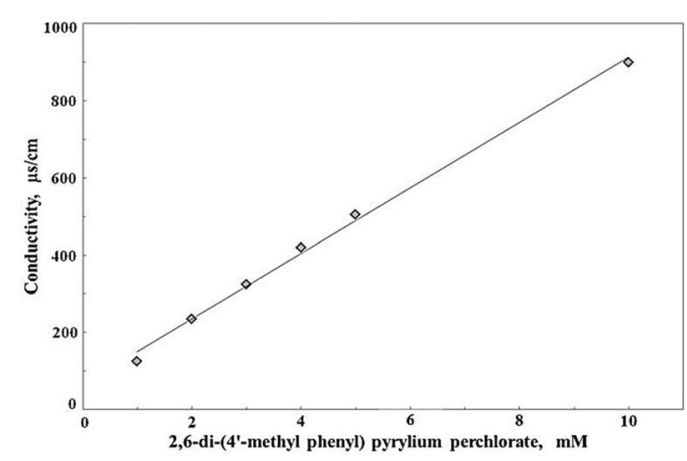

(b)

Fig. 8. Conductivity of 2, 6-di-(4'-methyl phenyl) pyrylium fluoroborate pyrylium fluoroborate (a), and 2, 6-di-(4'-methyl phenyl) pyrylium perchlorate (b). 


\section{CONCLUSIONS}

In this study, we synthesized 2,6-di-(4'-methyl phenyl) pyrylium fluoroborate and 2,6-di-(4'-methyl phenyl) pyrylium perchlorate in single step. In addition, their physical and optical properties were characterized. The $\lambda_{\max }$ identified from UV absorption spectra of the pyrylium salts was $439 \mathrm{~nm}$. Since the synthesized pyrylium salts have higher electron transferring capacity than traditional electrolytes, they can be used as a good sensitizer to detect ionic chemicals.

\section{ACKNOWLEDGMENT}

This research was supported by the 2009 Research Funds Program of the University of Seoul

\section{REFERENCES}

[1] A. T. Balaban, G. W. Fischer, A. Dinulescu, A. V. Koblik, G. N. Dorofeenko, V. V. Mezheritski, and W. Schroth, Editors, Pyrylium salts: Synthesis, Reaction and Physical Properties, Advanced in Heterocyclic Chemistry, Suppl. II, Academic Press, New York, 1982.

[2] T. H. Steinberg, L. J. Jones, R. P. Haugland, and V. L. Singer, "SYPRO orange and SYPRO, red protein gel stains: one-step fluorescent staining of denaturing gels for detection of nanogram levels of protein", Anal. Biochem., vol. 239, no. 2, pp. 223-237, 1996.

[3] G. Purvinis, P. S. Priambodo, M. Pomerantz, M. Zhou, T. A. Mal-donado, and R. Magnusson, "Secondharmonic generation in resonant waveguide gratings incorporating ionic self-assembled monolayer polymer Films", Opt. Lett., vol. 29, no. 10, pp. 1108-1110, 2004.

[4] I. Polyzos, G. Tsigaridas, M. Fakis, V. Giannetas, P. Persephonis, and J. Mikroyannidis, "Substituent effect on the photobleaching of pyrylium salts under ultrashort pulsed illumination", J. Phys. Chem., vol. B 110, pp. 2593-2597, 2006.

[5] K. Binnemans, "Ionic liquid crystals", Chem. Rev., vol. 105, pp. 4148-4204, 2005.

[6] M. Fakis, J. Polyzos, G. Tsigaridas, J. Parthenios, A. Fragos, V. Giannetas, P. Persephonis, and J. Mikroyannidis, "Novel class of pyrylium dyes with high efficiency in lasing and two photon absorption fluorescence", Chem. Phys. Lett., vol. 323, no. 1, pp. 111-116, 2000.

[7] D. Egan, M. Salmain, P. McArdle, G. Jaouen, and B. Caro, "FT-IR observation of covalent labelling of lysozyme crystals by organometallic complexes of transition metals", Spectrochim. Acta., vol. Part A 58, pp. 941-951, 2003.

[8] A. Diaspro and M. Robell, "Two-photon excitation of fluorescence for three-dimensional optical imaging of biological structures", J. Photochem Photobiol., vol B: Biol. 55, pp. 1-8, 2000.

[9] J. D. Tovar and T. M. Swager, "Pyrylium salts via electrophilic cyclization: applications for novel 3arylisoquinoline syntheses", J. Org. Chem., vol. 64, pp. 6499-6504, 1999.

[10] F. A. Scaramuzzo, A. Gonzalez-Campo, C. C. Wu, A. H. Velders, V. Subramaniam, G. Doddi, P. Mencarelli, M. Barteri, P. Jonkheijm, and J. Huskens, "Pyrylium monolayers as amino-reactive platform", Chem. Commun., vol. 46, no. 23, pp. 4193-4195, 2010.

[11] A. R. Katritzky, G. P. Savage, M. Pilarska, and Z. D. Szafran, "The synthesis and response to vapor challenges of new microsensor coatings pyridinium and pyrylim salts", Chem. Scr., vol. 29, pp. 235-239, 1989.

[12] M. R. Ganjali, M. Ghorbani, A. Daftari, P. Norouzi, H. Pirelahi, and H. D. Dargahani, "Highly selective liquid membrane sensor based on 1,3,5triphenylpyrylium perchlorate for quick monitoring of sulfate ions", Bull. Korean Chem Soc., vol. 25, no. 2, pp.172-176, 2004.

[13] B. G. Acosta, M. Comes, J. L. Bricks, M. A. Kudinova, V. V. Kurdyukov, A. I. Tolmachev, A. B. Descalzo, M. D. Marcos, R. M. Manez, A. Moreno, F. Sancenon, J. Soto, L. A. Villaescusa, K. Rurack, J. M. Barat, I. Escriche, and P. Amoros, "Sensory hybrid host materials for the selective chromo-fluorogenic detection of biogenic amines", Chem. Commun., vol. 21, pp. 2239-2241, 2006.

[14] G. J. Mohr, "Covalent bond formation as an analytical tool to optically detect neutral and anionic analytes", $J$. snb., vol. 107, pp. 2-13, 2005.

[15] N. Manoj, G. Ajayakumar, K. R. Gopidas, and C. H. Suresh, "Structure-absorption spectra correlation in a series of 2,6-dimethyl-4-arylpyrylium salts", J. Phys. Chem., vol. A 110, no. 39, pp. 11338-11345, 2006. 
[16] C. H. Chen, J. J. Doney, and G. A. Reynolds, "Synthesis and reactions of 2,6-diphenyl 4(trimethylsilyl)-4H-thiopyran", J. Org. Chem., vol. 47, no. 4, pp. 680-684, 1982.

[17] G. N. Dorofeenko and L. V. Dulenko, "A new method for the construction of pyrylium and pyridine rings fused to derivatives of furan and indole", Chem. Heterocycl. Compd., vol. 5, no. 3, pp. 417-421, 1969.

[18] W. Schroth, R. Spitzner, and E. Kleinpeter, "2,4,6 -tris (dialkylamino) pyrylium salts and related systems, synthesis and reaction behavior", Tetrahedron Lett., vol. 29, pp.4695-4698, 1988.

[19] S. V. Krivun, A. I. Buryak, and S. N. Baranov, "Pyrylium salts from pyrones and some organometallic compounds", Chem. Heterocycl. Compd., vol. 9, no. 10, pp.1191-1194, 1973.

[20] T. S. Balaban and A. T. Balaban, Science of Synthesis; Houben-Weyl Methods of Molecular Transformations,
Georg Thieme Verlag, Stuttgart, 2003.

[21] C. Mahler, U. Muller, W. Muller, V. Enkelmann, C. Moon, G. Brunklaus, H. Zimmermann, and S. Hoger, "Synthesis of highly phenylene substituted pphenylene oligomers from pyrylium salts", Chem. Commun., vol. 39, pp. 4816-4818, 2008.

[22] I. A. Levitsky, K. Kishikawa, S. H. Eichhorn, and T. M. Swager, "Exciton coupling and dipolar correlations in a columnar liquid crystal: photophysics of a bentrod hexacatenar mesogen", J. Am. Chem. Soc., vol. 122, no. 11, pp. 2474-2479, 2000.

[23] S. E. Okan, D. C. Champenev, and J. Solut, "Molar conductance of aqueous solutions of sodium, potassium, and nickel trifluoro-methane sulfonate at 25 'C", Chem., vol. 26, pp. 405-414, 1997.

[24] R. E. Johnson, Solute and Cathode Investigations in Propylene Glycol Sulfite, Lewis Research Center, Langley, 1967.

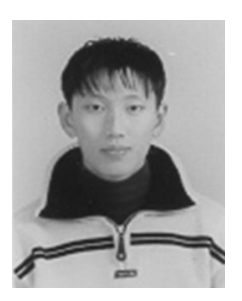

Jinhyeong Wie received his B.S. degree in environmental engineering from Daejin University, Korea, in 2004. He is currently working toward a M.S. degree inEnergy and Environmental System Engineering, University of Seoul, Korea. His research filed is Biological wastewater treatment and process control.

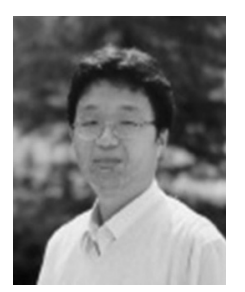

Hyunook Kim received his B.S. degree in environmental engineering from Yonsei University, Korea, in 1994 and his M.S. degree in Geography Environmental Engineering from the Johns Hopkins University, in USA, in 1997. In 2000, he received his Ph.D. degree in civil environmental engineering from University of Maryland, the USA. Now, he is on working in the University of Seoul with the professor. Presently, he takes on the Research Journal of Chemistry and Environment chief editor.

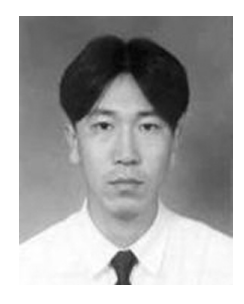

Young-Min Hong received his B.S. and M.Sc. degrees in environmental science from Kangwon National University, Korea, in 1999 and 2002, respectively. He finished the doctorate course in environmental engineering from University of Seoul, Korea, in 2009. He is currently working in the technology research institute in the Dong-Il SHIMADZU corporation. His research filed is environmental chemistry and instrumental analysis.

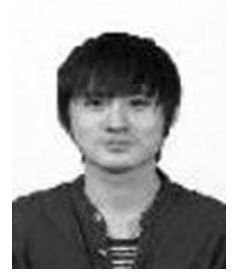

Kyung-Hoon Kim received his B.S. degree in chemical engineering from University of Seoul, Korea, in 2010. His research filed is Organic Light Emitting Diodesandsensitizer of electrical organic materials. 


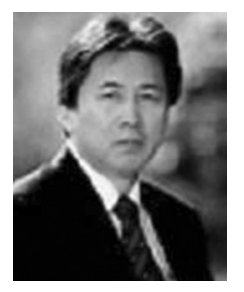

Sung-Il Cho received his B.S. degree in chemical engineering from Dongguk University, Korea, in 1974 and his M.Sc. degree in chemistry from Seoul National University, Korea, in 1976. In 1981, he received his Ph.D. degree in chemistry from Seoul National University, Korea.

His field of specialization is the crystallography, CVD semi-conductor, and inorganic chemistry. $\mathrm{He}$ is a lifetime member of the KCS, since 1975. 